\title{
The Time Local Convex Hull (T-LoCoH) method as a tool for assessing responses of fauna to habitat restoration: a case study using the perentie (Varanus giganteus: Reptilia: Varanidae)
}

Cross, S.L., Tomlinson, S., Craig, M.D., Dixon, K.W. and Bateman, P.W. (2020). The DOI: doi.org/10.1071/ZO19040

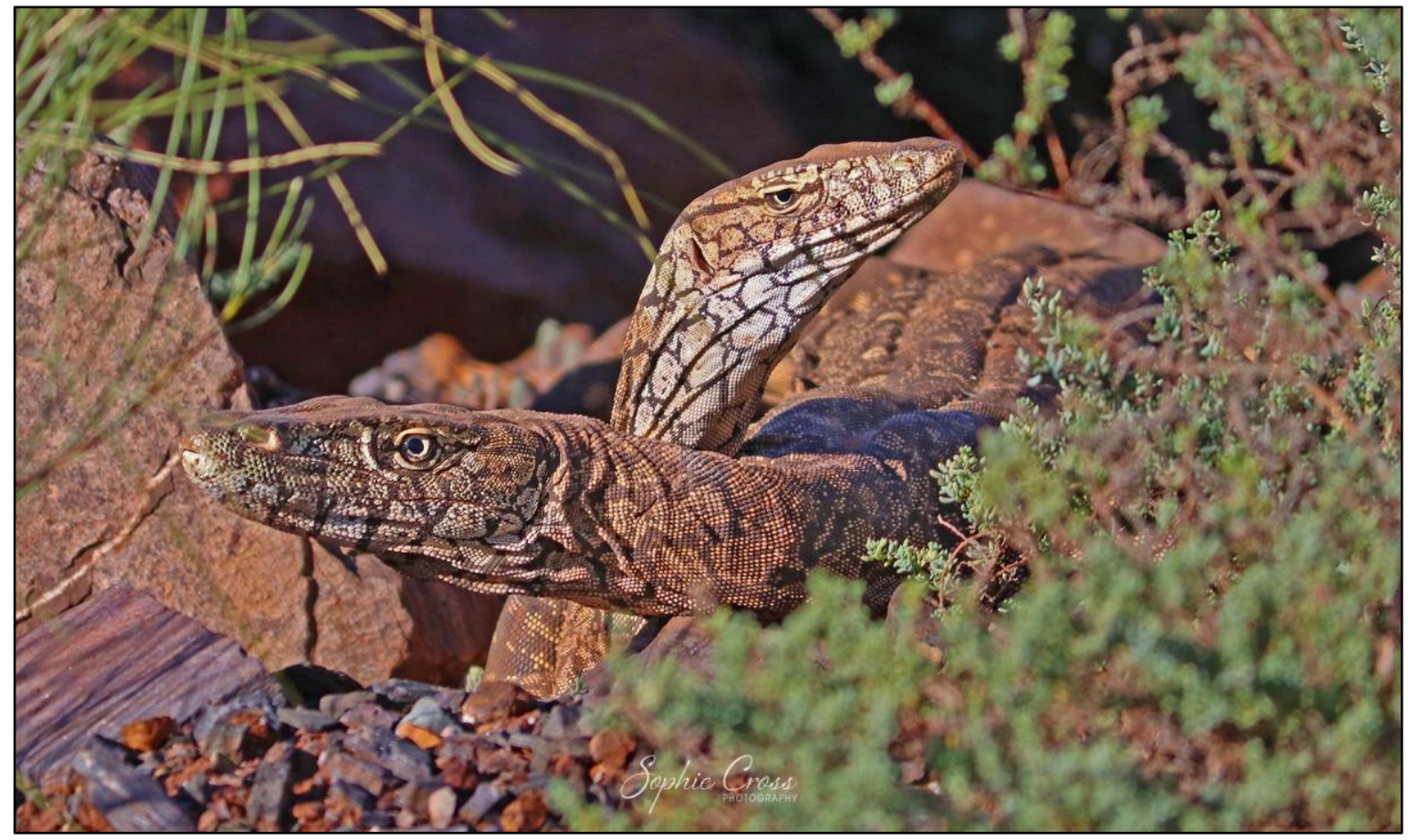

'Petra' the perentie (Varanus giganteus) and her mate (C) Sophie Cross 


\begin{abstract}
Understanding the behavioural responses of animals to habitat change is vital to their conservation in landscapes undergoing restoration. Studies of animal responses to habitat restoration typically assess species presence/absence; however, such studies may be restricted in their ability to show whether restoration is facilitating the return of self-sustaining and functional fauna populations. We present a case study using VHF/GPS tracking of a young adult perentie (Varanus giganteus), to demonstrate the range of applications of the Time Local Convex Hull method of home range construction in analysing the behavioural responses of fauna to habitat change and restoration. Presence/absence studies provide single point locations of an animal, and the Minimum Convex Polygon method provides an invariant estimate of habitat use across the whole home range. However, the Time Local Convex Hull method provides a useful method for assessing movement and behavioural responses of fauna to habitat change and restoration, and the specific habitat requirements for the long-term support of populations. The breadth and multidimensionality of data generated indicates strongly that understanding the complex interactions between animals and their environment is fundamental to their conservation in the face of ever-increasing rates of human induced habitat change and degradation.
\end{abstract}

\title{
Introduction
}

Habitat loss and degradation are leading drivers of species declines globally (Dobson et al., 1997). As we enter the Earth's sixth mass extinction event (largely anthropogenically driven; Kingsford et al., 2009), conservation efforts to aid in the mitigation of human-induced landscape change are becoming increasingly vital. Reptiles are experiencing global declines, largely driven by a loss and degradation of suitable habitat, through human influences such as industrialisation, urbanisation, mining, and agriculture (Böhm et al., 2013; Webb et al., 2014). Ectothermic animals, such as reptiles, rely on their habitat to regulate body temperature, and are thought to be at especially high risk of declines through changes in habitats and thermal environments (Ihlow et al., 2012). Reptiles are often overlooked in assessments of habitat change and restoration, and among existing studies there is a focus towards assessments for species diversity, presence, or abundance (Lindell, 2008; Cross et al., 
2019). These studies have several limitations, namely in their inability to account for the varying life history strategies of animals that alter their behavioural responses to habitat change (Lindell, 2008; Chiarucci et al., 2011). Understanding the processes driving the responses of reptiles to habitat alteration and restoration, in addition to assessments of their presence or absence from these systems, is vital to their conservation in the face of ever-increasing rates of habitat degradation and loss (Heard et al., 2004; Seebacher and Franklin, 2012).

Behavioural ecology and habitat selection are key to understanding the fundamental resource requirements for long term persistence of fauna within ecosystems (Ims, 1995; Mauritzen et al., 2003). Understanding the factors behind how fauna adapt and respond to varying habitat and climatic conditions, such as increasing temperatures and habitat fragmentation, is essential in forming predictions of how they may cope with habitat change and degradation into the future (Tuff et al., 2016). This has critical applications for reptiles as climate change alone is predicted to drive extinction rates as high as $20 \%$ by 2080 (Sinervo et al., 2010) and, in addition to a shifting climate, changing vegetation cover can markedly alter the thermal landscape and the availability of refuges for thermoregulation (Attum and Eason, 2006). Thermoregulatory ability of reptiles is strongly influenced by microclimates within their habitat, and their survival is highly dependent on an availability of spatially heterogeneous habitats with high resource abundance (Hertz et al., 1993; Basson et al., 2017). Predation pressures and metabolic costs can strongly impact the fitness and foraging efficiency of animals (Lima and Dill, 1990). Lima and Bednekoff (1999) propose that animals will preferentially forage within habitats perceived as 'low-risk' environments and exhibit antipredator behaviour and reduced foraging activity in higher-risk areas. Therefore, particularly for ectothermic species, in hot, open landscapes (higher risk environments), the trade-offs between time spent in thermoregulatory behaviour and time spent foraging can be high (Tuff et al., 2016).

Biotelemetry using VHF (Very High Frequency) and GPS (Global Positioning System) tracking provides an effective method of recording data for assessments of animal behaviour and movement patterns over multiple spatial scales (Obbard et al., 1998). Biotelemetry can provide detailed information on an animal's ecology, including its home range, use of the habitat, responses to the thermal environment, and 
activity, with minimal stress or intrusion to the animal (Cooke, 2008). Previous methods of analysing data from bio-telemetry approaches have largely been restricted to the construction of home ranges using the minimum convex polygon method (MCP; Worton, 1987). While providing important ecological data the MCP method does not account for the influence of environmental factors on home range and movement, such as temperature and vegetation structure, and does not show differential use of the home range or whether the entirety of the home range is in use (Worton, 1987). Other attempts of modelling home ranges have sought to define core or larger space-use areas (e.g., Kernel Density Estimates (KDE); Laver and Kelly, 2008), however the assumptions concerning the distribution of the point data are often violated, thereby over-estimating home ranges (Getz et al., 2007; Laver and Kelly, 2008).

Methods for analysing home-range data are constantly evolving, and recent years have seen the implementation of increasingly complex statistical algorithms for assessing home range and habitat selection by animals (Lele et al., 2013), including methods such as the Brownian Bridge Movement Model (BBMM), and the Time Local Convex Hull (T-LoCoH) method of home range construction, both of which have been used successfully to elucidate movements of animals within their home range (Byrne et al., 2014; Lyons et al., 2013; Tarszisz et al., 2018). T-LoCoH and the BBMM method not only include points of presence of an animal, but also include spatial and temporal information, allowing for a complex understanding of habitat use and behavioural ecology (Byrne et al., 2014). However, BBMM estimates movement paths between recorded locations of an animal and the probable location of an animal at any given time and may present an inaccurate reflection of behaviour and movement (Kranstauber et al., 2012; Ofstad et al., 2019). In comparison, T-LoCoH uses observed movement and can measure behaviour of animals in their habitat and uses a kernel modelling approach to identify areas that an animal visits repeatedly, which may represent core usage areas of the habitat, of which may be more profitable than others (i.e., contain an abundance of resources or refuges for thermoregulation; Lyons et al., 2013; Tuff et al., 2016) and are therefore visited frequently and for longer durations than non-core areas (Benhamou and Riotte-Lambert, 2012). Data extracted with either approach may be overlaid with environmental factors to show complex interactions of animals with their environment, providing a detailed understanding of behavioural and ecological responses to habitat change. Compared to assessments for species presence 
or absence, or home range analyses such as the MCP and KDE methods, T-LoCoH can aid in understanding the behavioural responses of fauna, including ectothermic animals, not only to habitat change and fragmentation, but to differing habitats and thermal environments. With globally increasing rates of anthropogenically-driven habitat change, understanding ecological, behavioural, and thermoregulatory responses are key to understanding how reptiles may respond to future changes, and to aiding future conservation efforts (Heard et al., 2004).

The perentie (Varanus giganteus, Reptilia: Varanidae) is Australia's largest lizard species, growing up to two and a half meters in length and weighing around $17 \mathrm{~kg}$ at maturity (Pianka, 1994; Pianka et al., 2004). Occupying terrestrial niches, perenties occur throughout much of arid Australia, from the Mid West region of Western Australia to far western Queensland (Pianka et al., 2004; Cogger, 2014). An apex predator, the perentie is active almost exclusively diurnally (during daylight hours) with activity typically highest during late spring and summer at temperatures averaging around $36^{\circ} \mathrm{C}$ (King et al., 1989; King and Green, 1993). Perenties tend to have large home ranges and forage over large areas (King et al., 1989), with distances of up to $900 \mathrm{~m}$ between consecutive locations of tracked perenties previously reported (Green et al., 1986). Importantly, due to their high mobility, they present an ideal study species to monitor thermal influences and habitat change over relatively large spatial scales.

Here, we report on the range of applications of the T-LoCoH method of home range construction for understanding the responses of fauna to habitat change and restoration using a young adult female $V$. giganteus as a case study. T-LoCoH has been used successfully in previous studies of animal movement, however these have been limited to either simulated data or mammalian studies, and have not sought to determine differential habitat use in altered or restored landscapes, but primarily spatial utilisation of home ranges (e.g., Lyons et al., 2013; Stark et al., 2017), with one ecophysiological study of movement and seed dispersal (Tarszisz et al., 2018). Here we discuss how T-LoCoH can be applied to ectothermic animals and studies of conservation, habitat alteration, and ecophysiology. We aim to assess how T-LoCoH may be applied in assessments of habitat use, movement, and activity of a perentie within reference (bushland not directly impacted by mining activities) and 
anthropogenically-altered habitats. We hypothesise that the T-LoCoH method will provide an effective measure for understanding the mechanisms driving behavioural and ecological responses of fauna to altered habitats, which should facilitate their future conservation in the face of increasing rates of habitat degradation and loss.

\section{Methods}

\section{Study Site and Species}

We conducted our study in the Mid West region of Western Australia at an area undergoing restoration within a major magnetite mining operation, approximately 430 km northeast of Perth $\left(29^{\circ} 08^{\prime} 50.3^{\prime \prime S} 116^{\circ} 49^{\prime} 07.5^{\prime \prime E}\right.$, Fig. A, B). Restoration of a waste rock dump (an area of $\sim 0.5 \mathrm{~km}^{2}$ ), situated $8 \mathrm{~km}$ north of the current mining activities within the study area, commenced in May 2014 (earthworks and seeding), with the completion of all seeding by July 2017. The study site (Fig. 2) experiences an arid climate, with temperatures in late spring typically ranging between $27^{\circ} \mathrm{C}$ and $37^{\circ} \mathrm{C}$ (Australian Bureau of Meteorology, http:// www.bom.gov.au/climate/data/). Vegetation within the study area largely comprises Acacia shrublands and open Eucalyptus woodlands (Bamford, 2006), with the restoration habitat comprising a similar species composition. However, vegetation in the restoration area is at varying stages of establishment and lacks the spatial heterogeneity of the reference habitat (Fig. 3). We sought to catch adult perenties between October and November 2018, using cage trapping, noosing, and other methods of hand capture (Flesch et al., 2009; García-Muñoz and Sillero, 2010). We imposed a constraint that the ratio of tracker to body weight was $<4 \%$ of the varanid's total body weight to minimise adverse effects to the animal's fitness or a reduction in movement (Flesch et al., 2009). Shy and elusive, perenties can be difficult to capture (Pianka, 1994; Moro and MacAulay, 2014), and we only succeeded in capturing a single $V$. giganteus individual large enough to outfit for telemetry; a young adult female (head width: $35 \mathrm{~mm}$, head length: $85 \mathrm{~mm}$, snoutvent length: $495 \mathrm{~mm}$, total length: $1215 \mathrm{~mm}$, body weight: $2.1 \mathrm{~kg}$ ). We tracked its movements for a period of 20 days from the $8-28$ of November 2018, ending when it shed the transmitter. 


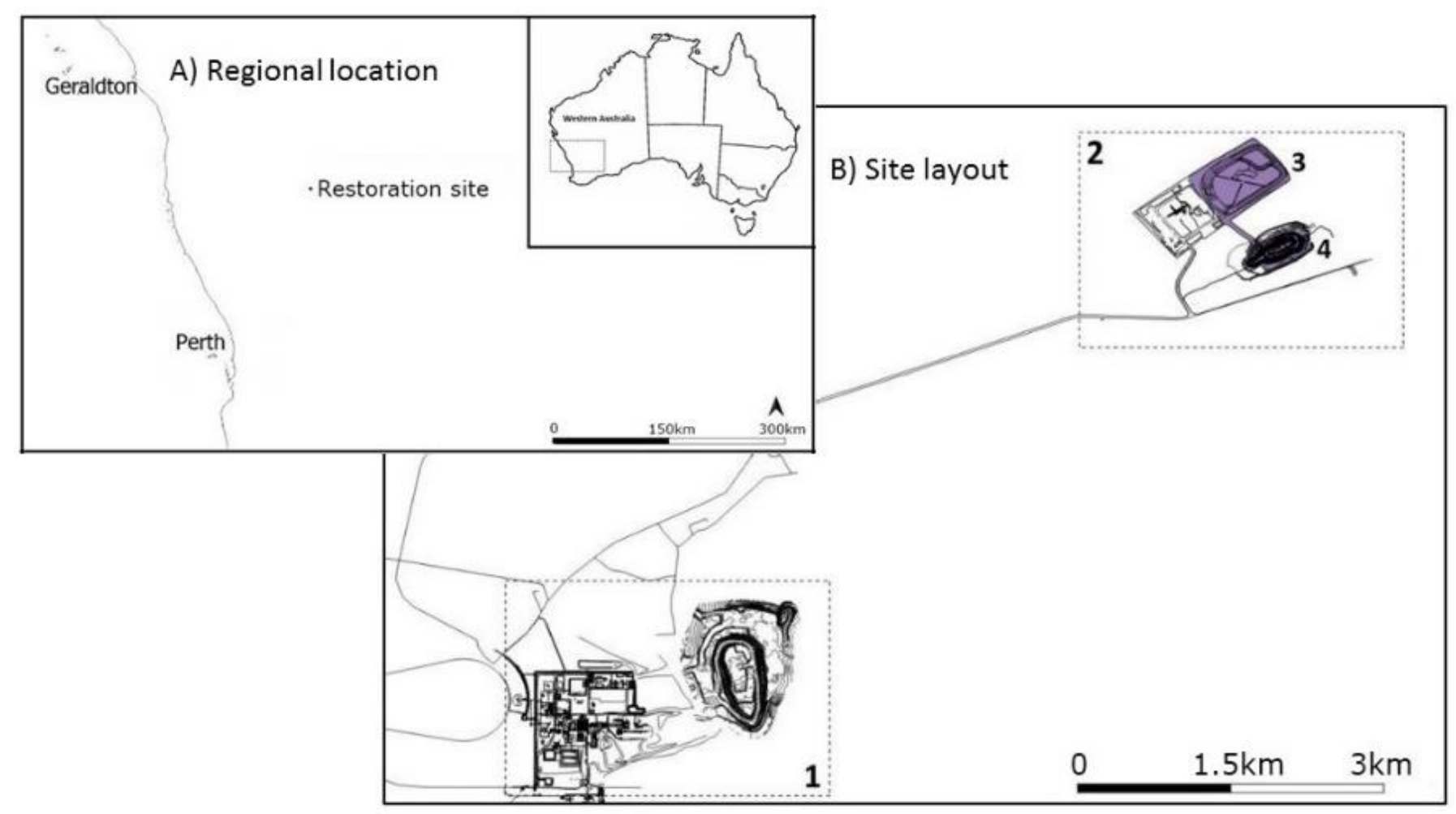

Fig. 1: A) The location of the study site in the Mid West region of Western Australia, and B) the site layout, comprising the location of active mining activities (1), and the restoration project (2), which is characterised by two areas of anthropogenic disturbance, the restoration of a waste rock dump (3) and a disused mine pit void (4), surrounded by otherwise unmined habitat. The study site is roughly $8 \mathrm{~km}$ distant from the current active mining operations and our findings are unlikely to have been influenced directly by that activity. 


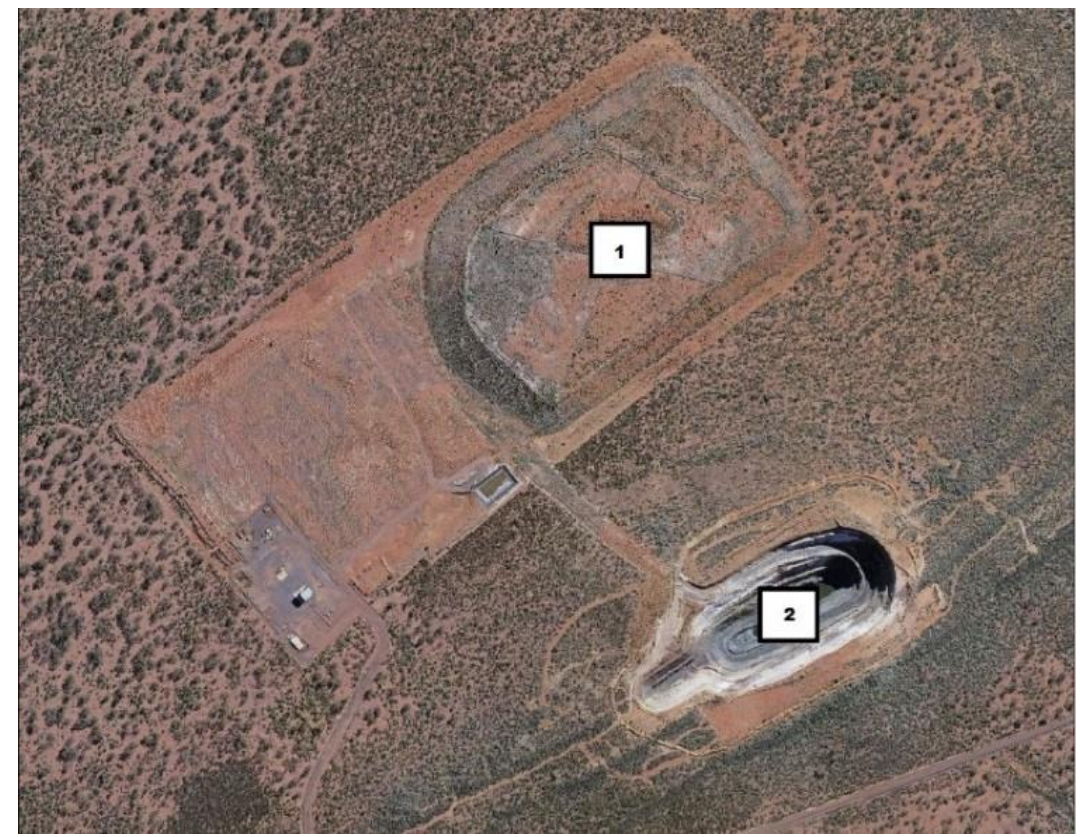

Fig. 2: An aerial view of the study site, characterised by (1) the restoration waste rock dump, and (2) the disused mine pit, surrounded by reference habitat.

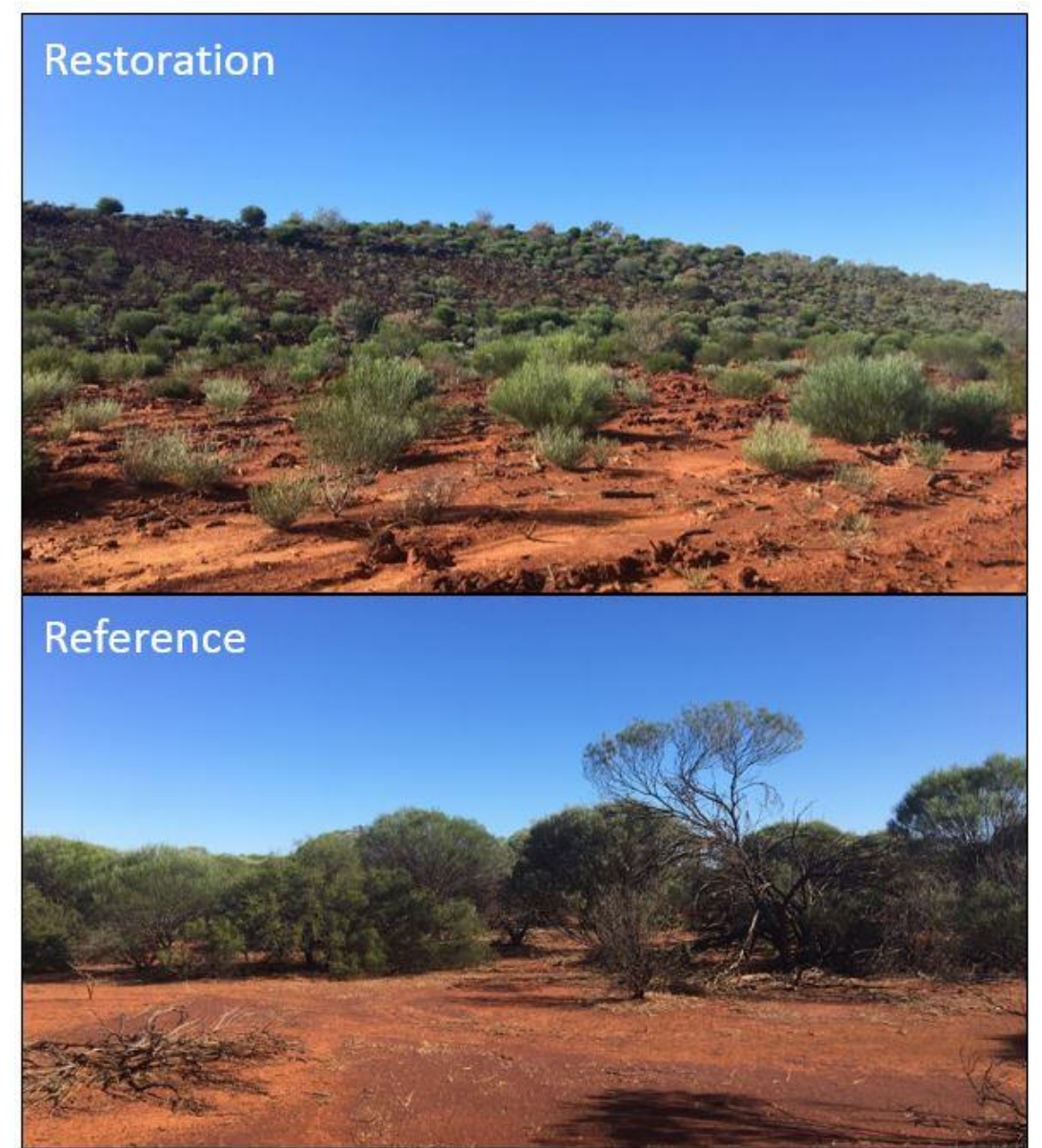

Fig. 3: Typical vegetation structure within restoration and reference habitats. Restoration vegetation is at varying stages of establishment and cover is reduced in comparison to the reference vegetation. 


\section{Transmitter Attachment and Tracking}

The perentie was fitted with a W510 Wildlink Wireless GPS/VHF tracking unit (50 x 40 x 10mm, 65g; Advanced Telemetry Systems, Australia). The tracker was affixed to its dorsal surface with non-toxic, quick drying superglue (Fig. 4), and the edges of the tracker were covered with cloth tape to reduce the likelihood of the tracker catching on debris or being dislodged (Price-Rees and Shine, 2011). As perenties are not considered to be nocturnally active (King and Green, 1993), the GPS logger was programmed to take 58 fixes per day, with quarter hourly fixes during daylight hours (between 0600hrs and 1900hrs), and one fix every two hours overnight (between $1900 \mathrm{hrs}$ and $0600 \mathrm{hrs}$ ). As we were tracking a single animal, the GPS was programmed to record the maximum number of fixes during periods of high activity, to attain a thorough and consistent dataset of the perentie's movements throughout its home range. Transmitters recorded date and time of fix, activity of the perentie (the number of minutes the perentie was active for during the 15 minutes prior to each fix, recorded as a percentage), and ambient temperature (temperature of the tracking device at the time of the GPS fix recording). Activity was recorded internally within the GPS unit via a switch activated upon movement of the animal, which continually reset every 15 minutes when a new fix was recorded.

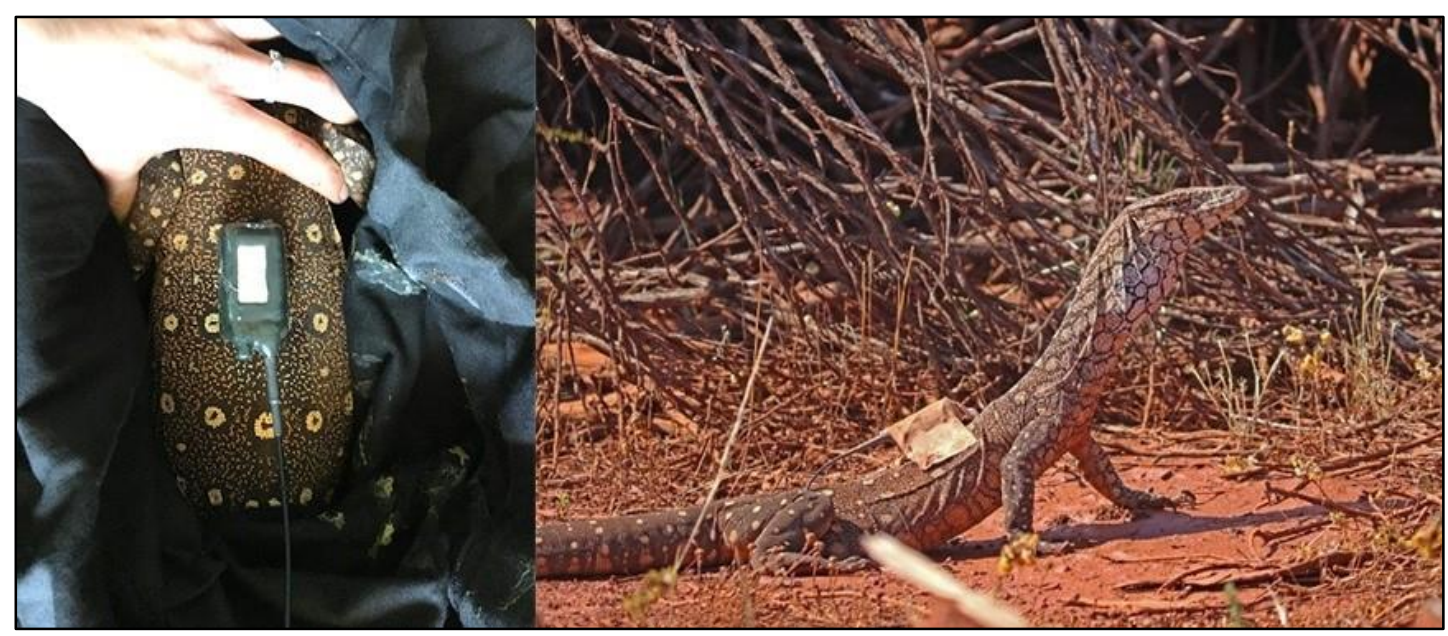

Fig. 4: The tracking unit affixed to the back of a perentie (Varanus giganteus). Left: the unit attached on the middle of the dorsal surface, set just behind the line of the forelimbs to minimise the likelihood of the varanid dislodging the tracker, and right: the perentie observed in situ basking next to a fauna refuge in the restoration area, with the telemetry package and cloth tape covering (Photographed by S. Cross). 
Following tracker attachment, the perentie was released at the point of capture and VHF tracked with visual sightings for the remainder of the day to ensure its welfare. To maximise the likelihood of recapturing the perentie, attaining a download of fixes, or finding the tracker if it was shed, we conducted twice daily VHF tracking with an early morning track prior to $0800 \mathrm{hrs}$ to observe the lizard as it emerged from its burrow, and a late afternoon track to identify its nocturnal refuge. GPS fixes were remotely downloaded each morning upon location of the animal. Tracking ceased upon shedding of the transmitter (9.40am on 28 November 2018), at which time we observed the perentie engaged in mating behaviour and were able to confirm its sex as female. We concluded the tracker had no adverse effects on the perentie's health.

\section{Home Range and Movement Ecology}

We analysed the data on the movement patterns of the perentie using the T-LoCoH method to determine its home range, and influence of vegetation quality (reference or restoration) and temperature on movement within its habitat (Lyons et al., 2013). Analyses included all GPS points for which a successful fix could be attained via four or more satellites (Stark et al., 2017) and ultimately comprised 865 successful fixes (79\% of all data points) over a 20-day duration. Excluded data comprised 'zero fixes' where the perentie was underground in a burrow and GPS fix could not be recorded. As we were assessing daily movement patterns of the perentie, for the purposes of analysing frequency and duration of visits, we applied an inter-visit gap (IVG) of 12 hours following Lyons (2014) and, as such, points were only considered separate visits if a period of 12 hours or greater had passed from the previous visit.

T-LoCoH offers two methods in kernel modelling, the ' $k$ ' method, which standardises the number of nearest neighbours, and the ' $a$ ' method, which accounts for single excursions by an animal within its habitat and decreases sampling bias by 'reducing the number of nearest neighbours used in areas where points are thin and scattered' (Lyons, 2014). As our data comprised both heavily and sparsely utilised regions of the home range, we applied the $a$ (adaptive) method in the construction of hulls, following Lyons (2014). The a method decreases the likelihood of over-estimating use of particular areas of the home range (Lyons et al., 2013; Lyons, 2014). We computed hulls for a variety of $a$ values, and selected an $a$-value of 8000 as the model-of-bestfit based upon isopleth models and edge: ratio curves (Lyons, 2014). We used chi 
square tests to compare observed frequency (NSV; Number of Separate Visits) and duration of visits (MNLV; Mean Number of Locations in the Hull per Visit) within each area of the habitat with expected values, based on the proportional area of reference $\left(0.87 \mathrm{~km}^{2}\right)$ and restoration habitats $\left(0.31 \mathrm{~km}^{2}\right)$ within the perentie's home range.

\section{Activity and Temperature}

As data were not normally distributed or independent, we used a repeated measures ANOVA with a Greenhouse-Geisser correction to analyse differences in activity and temperature of the perentie between reference and restoration habitats. We recorded a high level of GPS fixes with an activity level of zero (where GPS recorded no active minutes in the 15 minutes prior to a fix), which largely represented time the perentie spent in or around a burrow. As such, we repeated our analyses with zero activity data points removed, to determine differences between usage of restoration and references habitats during the periods of time when the perentie was active within each habitat type. While ambient temperature recorded by the tracking device may not fully represent the perentie's body temperature, we used recorded temperatures to demonstrate how ecophysiological data may be integrated with $\mathrm{T}-\mathrm{LoCoH}$ to understand environmental constraints to movement. All analyses for home range and movement ecology were conducted in the $R$ v3.4.4 statistical environment (R Core Team, 2016), implemented using RStudio (RStudio, Inc, Boston, United States, 2019). All other analyses were conducted using SPSS Statistics version 25 (IBM, New York, United States).

\section{Results}

\section{Home Range and Movement Ecology}

We attained a total of 865 fixes, 503 within reference habitat and 362 within restoration habitat. Through the application of the T-LoCoH method, we identified the perentie's home range to cover $1.18 \mathrm{~km}^{2}$, in comparsion to the MCP which overestimates the home range at $2.002 \mathrm{~km}^{2}$ (Fig. 5). The perentie's home range had three distinct areas of core usage; one each within reference and restoration, and one on the edge of the reference and restoration habitats (Fig. 6A). These areas included the perentie's 
burrows and refuges, and appeared to be in alternating use, with each area of the core home range visited in rotation during the tracking period. However, usage of the refuge area on the border of reference and restoration vegetation (a designated fauna refuge area composed of piles of logs, vegetation, and soil) appeared to be opportunistic, used for only one time block (three days, $10^{\text {th }}$ to $13^{\text {th }}$ November 2018). Use of this area was associated with a storm and flash flooding event $(38 \mathrm{~mm}$ rainfall on 10 November 2018). Core areas of the home range were characterised by a high frequency of short duration visits (Fig. 6B, C). Usage of the remainder of the perentie's home range radiated from core usage areas. Points with long duration visits tended to occur on the edges of the perentie's home range, with shortest duration visits centring within the core usage areas.

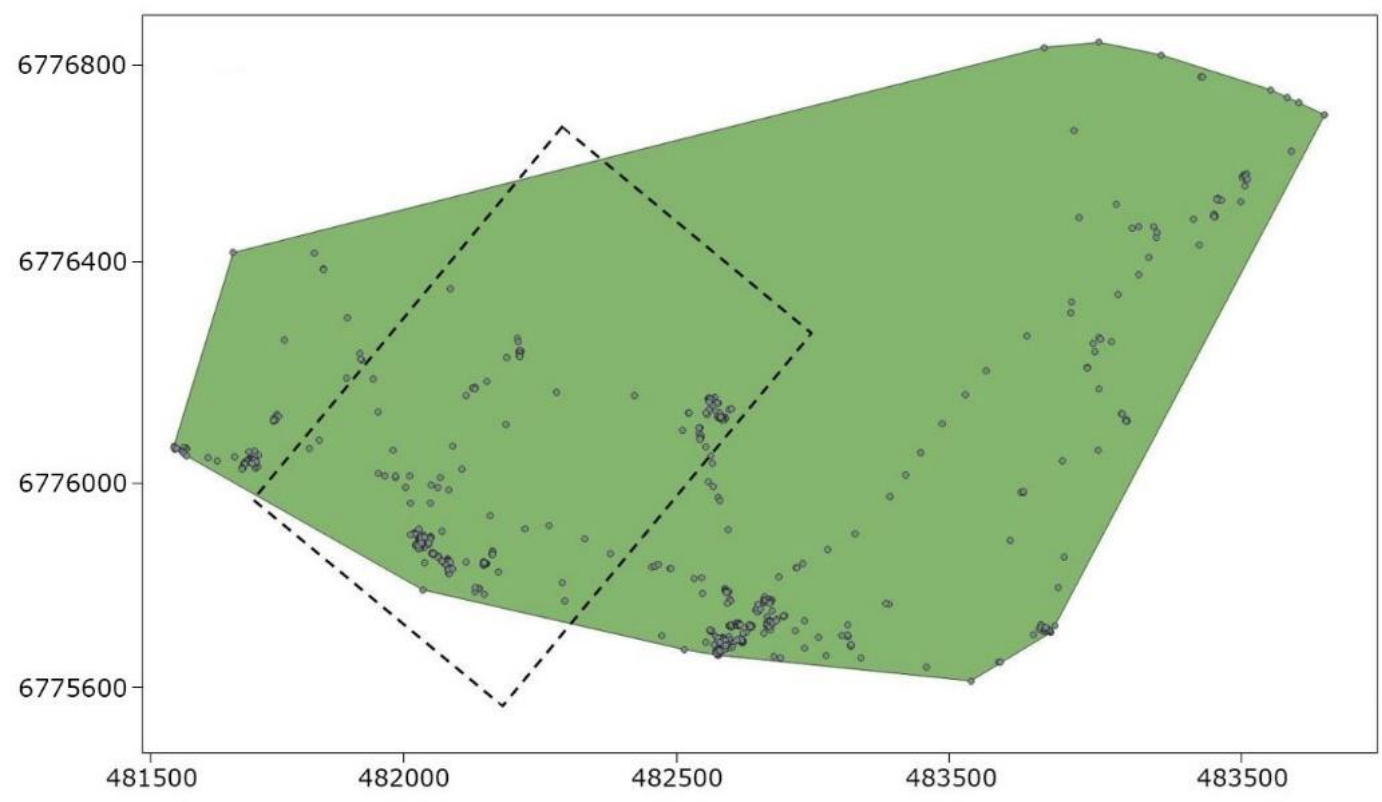

Fig. 5: An estimation of the perentie's home range using the Minimum Convex Polygon Method. The dashed rectangle comprises the points of utilization within the restoration habitat. X and Y axes represent UTM coordinates. 

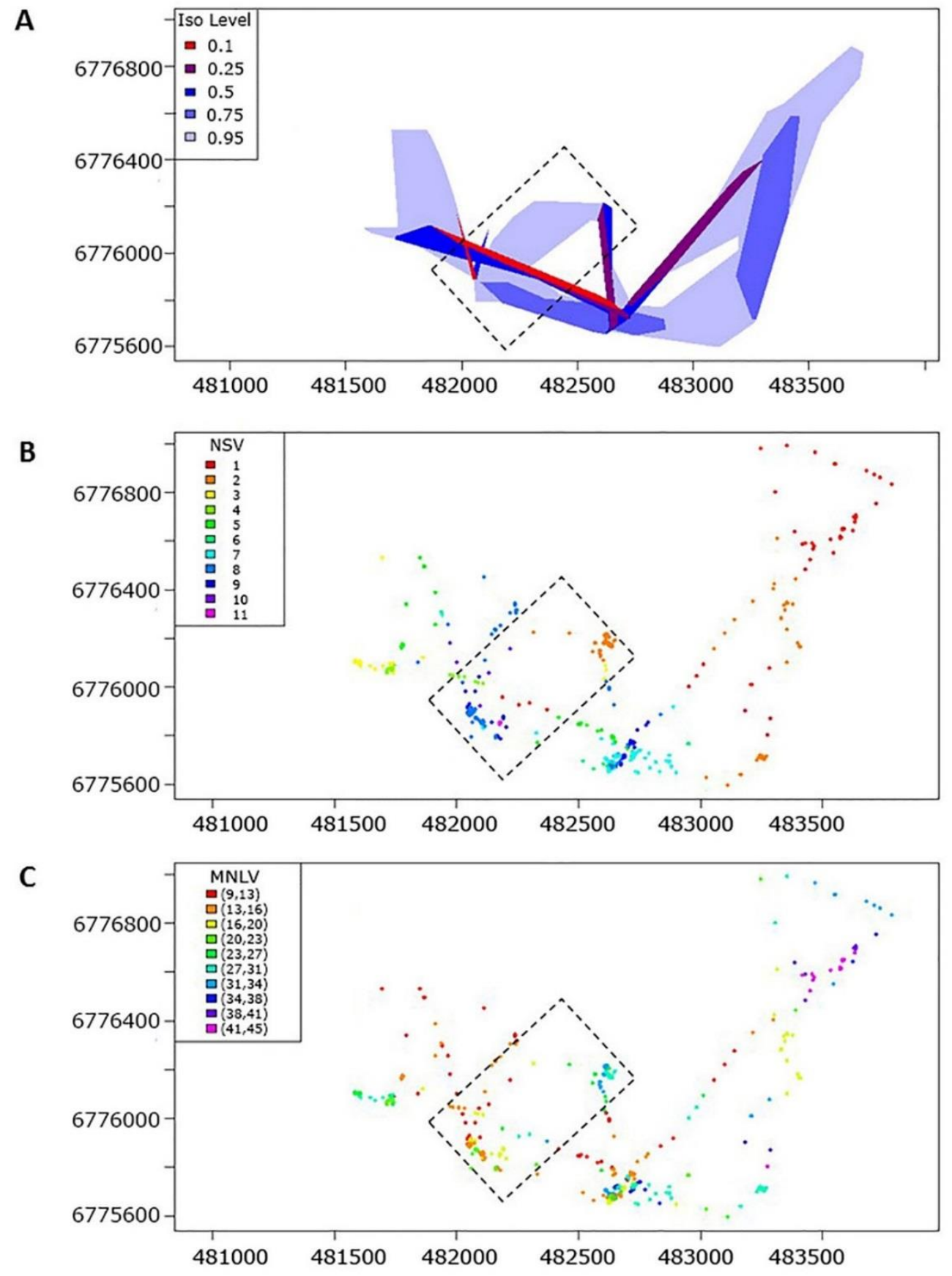

Fig. 6: Movement and behaviour of an individual $V$. giganteus: A) behaviour isopleths (density calculated from hull metrics: average point density falling within each hull) and core home range, B) number of visits (NSV; number of separate visits) to each point within the home range, and $\mathrm{C}$ ) duration of visits (MNLV; mean number of locations in the hull per visit). Points are considered 'separate visits' if the IVG $\geq$ $12 \mathrm{hrs}$. Behaviour isopleths show utilisation of regions of the home range, where higher iso levels indicate an increased likelihood of the varanid visiting a point within the hull (i.e. an iso level of 0.95 indicates a $95 \%$ chance of the varanid being located within this area at any given time within the sampling period). Density isopleths, frequency, and duration of visits were calculated using the $a$-method ( $\mathrm{s}=0.0075, a=8000)$. $\mathrm{X}$ and Y axes represent UTM coordinates. The dashed rectangle within each figure comprises the points of utilisation within the restoration habitat. 
Both reference and restoration habitats were utilised by the perentie; however, movement and activity varied considerably between the two habitats. Both frequency (NSV) and duration (MNLV) of visits differed significantly between reference and restoration habitats, with points in restoration visited frequently, but for shorter durations (NSV; $\chi 2=62.98$, d.f. $=1, P<0.001$, MNLV; $\chi 2=60.32$, d.f. $=1, P<$ 0.001). The perentie exhibited increased selectivity in use of restoration vegetation, typically traversing this area quickly and infrequently, venturing only short distances from the core usage area (Fig. 6B, C). The opposite was true within the reference habitat where usage was less selective. The perentie visited points within the core area of the restoration vegetation significantly more frequently than core areas in the reference vegetation $(\chi 2=351.33$, d.f. $=1, P<0.001)$, however for shorter durations $(\chi 2=400.85$, d.f. $=1 ; P<0.001)$. The same pattern was observed between non-core areas between reference and restoration areas of the habitat (NSV: $\chi 2=12.43$, d.f. $=$ 1, $P<0.001$; MNLV: $\chi 2=398.68$, d.f. $=1, P<0.001)$. Overall, points in core areas were consistently frequented more often, and for a reduced duration compared to those within non-core areas (Fig.7). The area within and immediately surrounding the disused mine pit was completely avoided.

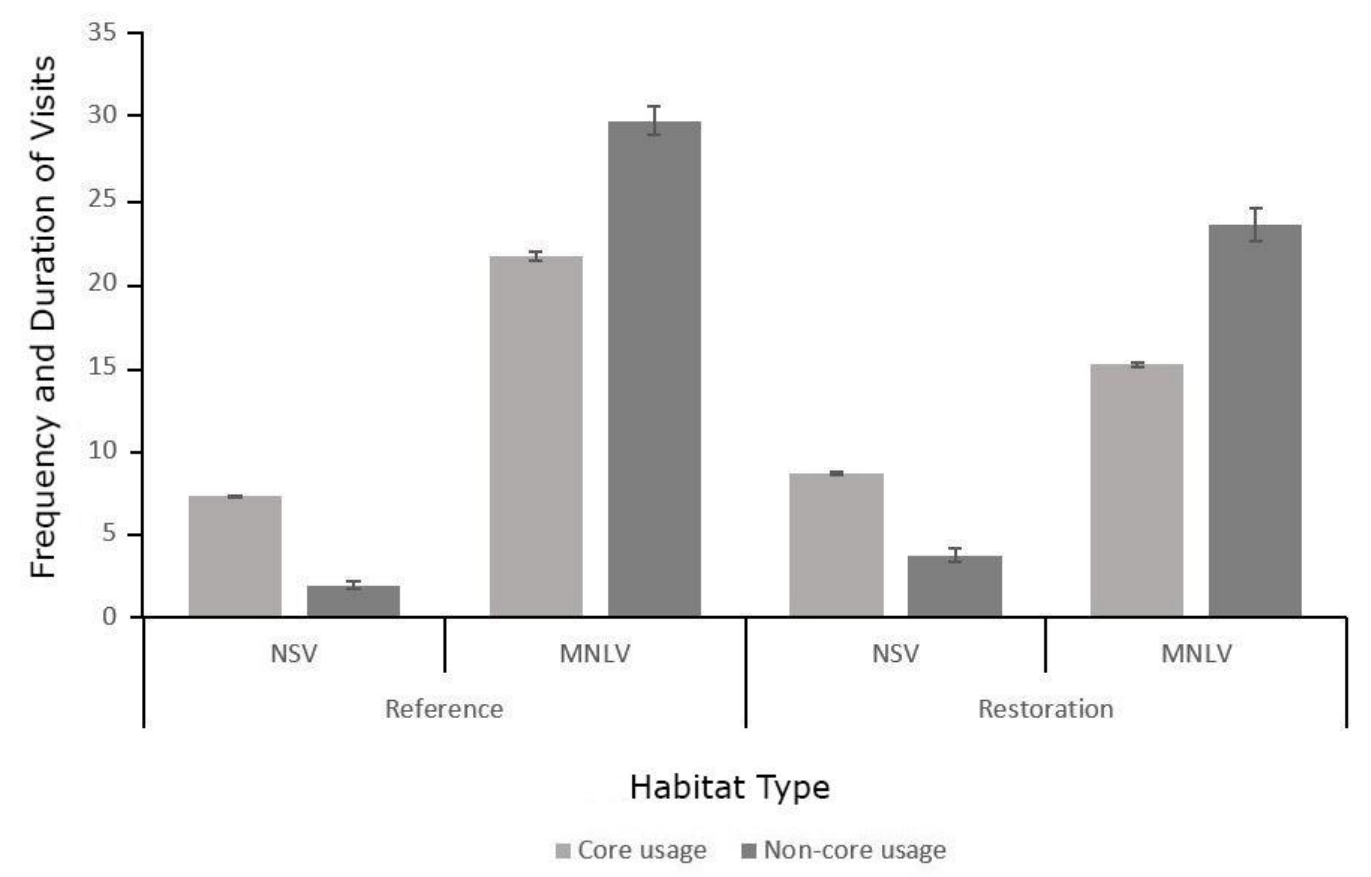

Fig. 7: Frequency (NSV: Number of Separate Visits) and duration (MNLV: Mean Number of Locations per Visit) of visits by the perentie to core and non-core usage areas within restoration and reference habitat. 


\section{Temperature and Activity}

Recorded active temperatures ranged from $21^{\circ} \mathrm{C}$ to $40^{\circ} \mathrm{C}$ in reference habitat and $23^{\circ} \mathrm{C}$ to $40^{\circ} \mathrm{C}$ in restoration habitat, averaging $34.1 \pm 0.14(\mathrm{SE})^{\circ} \mathrm{C}$ and $33.8 \pm 0.21(\mathrm{SE})^{\circ} \mathrm{C}$ respectively. Ambient temperatures at times of GPS fixes did not differ significantly between reference and restoration habitat $\left(F_{(1,361)}=0.60, P=0.439\right)$; however, activity level of the perentie was significantly higher in reference habitat $\left(F_{(1,361)}=95.60, P<\right.$ 0.001 ). Activity within reference habitat ranged from $0-78 \%$ (up to 12 of 15 minutes active), with an average of $6.7 \pm 0.56$ (SE)\%, while activity within the restoration vegetation ranged between from $0-64 \%$ (up to 9.5 minutes active), averaging $5.5 \pm$ 0.57 (SE) \% activity. The perentie was significantly more active within non-core usage areas within both reference $\left(F_{(1,114)}=91.62, P<0.001\right)$ and restoration habitats $\left(F_{(1,89)}\right.$ $=45.33, P<0.001)$, however between the two areas, activity in non-core areas tended to be higher in reference habitat, while activity in core areas was higher within restoration habitat (Fig. 8). The perentie spent approximately two thirds of its time in core-usage areas within each habitat. Daily patterns for temperature and activity of the perentie within reference and restoration vegetation is summarised in Fig. A4.1a,b, c (Appendix 4).

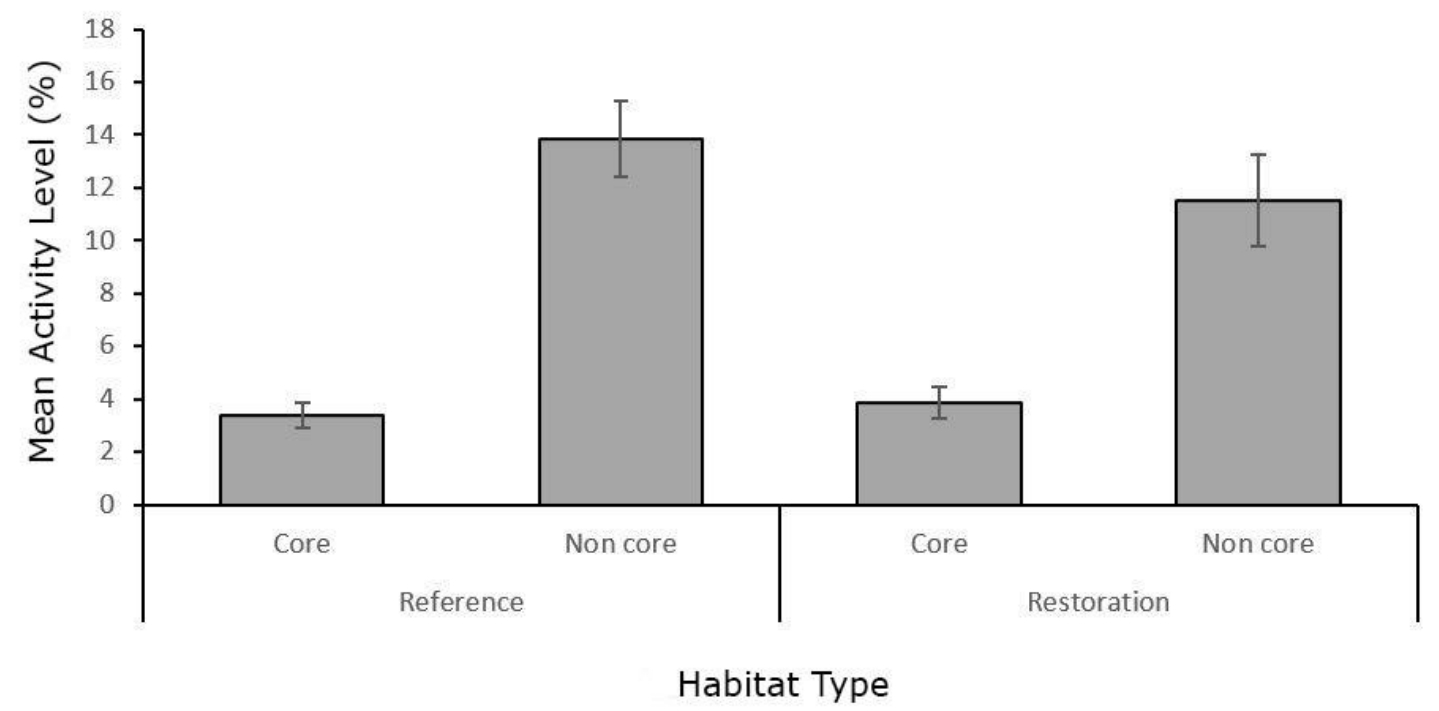

Fig. 8: Mean activity levels of the perentie within core and non-core usage areas of the reference and restoration habitat. 


\section{Discussion}

The extent to which conclusions for ecological responses to habitat alteration may be drawn from a single animal are limited; however, T- $\mathrm{LoCoH}$ outputs provide a breadth of data and can aid in identifying potential mechanisms driving complex ecological interactions between animals and their environment. The movement ecology of Australian varanids has attracted sporadic attention over several decades (e.g., King, 1980; Guarino, 2002; Flesch et al., 2009); however, little is understood of how these animals use either reference habitats, or anthropogenically impacted landscapes. While we are limited in drawing ecological implications by our sample size, application of T-LoCoH not only allowed for the construction of the total home range of the perentie, but in understanding the complex spatial and temporal use of restoration and reference areas habitat, such as frequency and duration of visits to points in the home range, and temperature and activity at each point, aiding in understanding the potential motivators of the responses of the perentie to habitat alteration and restoration.

\section{Home Range, Movement, and Behaviour}

The perentie's home range comprised three main areas of usage; the main burrow within reference habitat, a burrow on the southern side of the restoration waste rock dump, and a burrow on the edge between reference and restoration vegetation. Several Varanus species have previously been documented using multiple burrows or refuges such as hollow logs, termite mounds, and trees (for example, V. panoptes, $V$. bengalensis, and V. salvator; Wikramanayake and Dryden, 1993; Doody et al., 2014). In addition to providing overnight refuges, burrows aid in the regulation of body heat and water and provide a refuge during periods of aestivation (Green, 1972; Vernet et al., 1988; Doody et al., 2014). Both reference and restoration habitats contained core usage points; however, actual usage across the home range differed significantly between each habitat. Despite $42 \%$ of all GPS fixes originating within restoration habitat, spatial use of this area was restricted and 65\% smaller than usage in reference habitat $\left(0.31 \mathrm{~km}^{2}\right.$ in restoration vegetation, compared to $0.87 \mathrm{~km}^{2}$ in reference vegetation). Outside of the core area, usage of restoration was limited with many areas either traversed infrequently, or completely avoided. Assessing the frequency and duration of visits an animal makes to points in the habitat is vital to understanding movement within, and use, of its home range (Benhamou and Riotte-Lambert, 2012). 
Restoration can require significant periods of time before it resembles reference habitats, and habitats lacking established vegetation cover typically present unfavourable conditions and inadequate refuges or microclimates for thermoregulation, all of which may have made the restoration less attractive to the perentie, and account for its movement patterns (Tuff et al., 2016). King (1980) notes that the activity patterns of several Varanus species may be strongly impacted by vegetation cover, with open and homogenous landscapes presenting increased thermal costs and restricting movement during peak temperatures.

Temperature and its effects on thermoregulation and fitness are well-studied in many reptile species (e.g., Chelazzi and Calzolai, 1986; Hertz et al., 1988; Schwanz and Janzen, 2008). Some studies have assessed the relationship between body temperature and activity of varanids (e.g., Christian and Weavers, 1994, 1996); however, the relationship between landscape degradation and subsequent restoration, and thermoregulatory behaviour of ectothermic animals has rarely been studied (Tuff et al., 2016). Assessing the relationship between thermal landscapes and thermoregulatory behaviours of reptiles at a variety of spatial scales is important to understanding habitat use and the factors impacting habitat selection (Row and BlouinDemers, 2006). By overlaying environmental temperature recordings with our perentie's movement data in T-LoCoH, we demonstrated an effective method for analysing how habitat degradation and restoration may impact thermoregulatory behaviour and movement. Studies that do not account for environmental factors may conclude that, due to both habitats recording similar temperatures, temperature is not a constraint within restored habitats. Although ambient temperature may not fully represent body temperature, our data suggest that movement and activity patterns of the perentie within, and between, each habitat type differed significantly, despite ambient temperature not differing significantly between the habitats. We note high selectivity of habitat use by the perentie in restoration habitat, with this area functioning largely as a shelter site, whereas reference habitat facilitated increased movement and longer distance and duration foraging trips. Sears et al. (2011) notes that spatial heterogeneity in the thermal landscape can influence thermoregulatory costs, even in situations where temperatures within a landscape do not differ statistically. Particularly for ectothermic animals, where temperature and metabolic 
costs can be significant constraints to movement, understanding how temperature affects movement and activity within altered habitats is vital to their conservation.

\section{Benefits of T- LoCoH and GPS Technology}

Compared to the insights that we gained using the T-LoCoH method, conclusions drawn from our data based upon only points of presence of the perentie would have resulted in a significant misrepresentation of the perentie's home range (activity area). To begin with, the home range estimated by the MCP method was 170\% larger than that estimated by T-LoCoH, with almost the entirety of the restoration area included in the home range. Over-estimation of home ranges is a common issue reported for studies using the MCP method (Pimley et al., 2005; Ciofi et al., 2007; Downs and Horner, 2008). Furthermore, roughly half of all GPS fixes for the perentie's movements were recorded within restoration, and a study of species presence alone would conclude similar use of both habitats. Through applying the T-LoCoH method, we identified that, although facilitating return of the perentie, the restoration was used with greater selectivity in comparison to reference habitat, supporting shorter distance and duration movement. Presence/absence studies, by comparison, are limited in their ability to provide an understanding of the environmental influences driving behavioural responses to habitat alteration, or in understanding movement of animals through landscapes (Mackenzie, 2005; Cross et al., 2019). T-LoCoH provides a reliable method for identifying points of the habitat that are used frequently compared to those that are visited infrequently or only in opportunistic use. For example, our data suggested that while the perentie frequented parts of the restoration vegetation, several areas including the top of waste rock dump appeared to be avoided. This area of the habitat tended to comprise sparse vegetation and increased spatial homogeneity, and as such was likely avoided by the perentie due to a lack of appropriate microclimates for thermoregulatory behaviours. Understanding the behavioural responses of animals to changing habitats, particularly those which may have increased susceptibility to fluctuating temperatures, is key to facilitating their conservation in altered landscapes undergoing restoration (Cross et al., 2019).

In assessments of home ranges and movements of animals, VHF tracking alone is less effective than when combined with GPS technology, due to its tendency to cause significant disruption to the study animal and its natural behaviour (Cooke et al., 2004; 
Thomas et al., 2011). VHF tracking also requires multiple relocations of the animal each day to understand movement ecology, and hence constant human presence can disrupt natural behaviour and may result in a false representation of habitat use. Combining GPS technology with the T-LoCoH method allowed the collection of continuous data on the perentie's movements with minimal impact to the natural behaviour of the animal, due to requiring comparatively infrequent locations by people. Furthermore, T-LoCoH reduces the impacts of temporal autocorrelation on data through the incorporation of an IVG component, and visits to points of the habitat are only considered separate if a period greater than the IVG has elapsed between samples (Lyons, 2014).

Ecological and behavioural responses may differ between individuals and our data may not reflect responses of the wider population of $V$. giganteus, particularly since our focal animal was a young adult, and hence may have a smaller home range than that of an adult individual, as has previously been reported among studies of reptile home range (e.g., Semlitsch, 1981; Diemer, 1992; Rocha, 1999). Regardless, our study demonstrates how VHF and GPS tracking provides a depth of data and a measure of continued assessments of movement ecology which, through the application of the T-LoCoH method, can aid in understanding movement and behavioural responses of animals to habitat change and restoration. In assessments of faunal responses to habitat change and restoration, measures of species presence, absence, or abundance, or construction of simple spatial home ranges are unlikely to adequately show whether restoration sites are facilitating long-term use and population persistence (Cross et al., 2019). However, T-LoCoH can show whether habitat restoration is supporting natural behaviour, or whether it provides suboptimal habitat for support of animal populations. Although conclusions drawn concerning the success or failure of restoration efforts from a single animal may not be valid, data from our study suggest that while restoration is facilitating return, these areas are used with increased selectivity, and behaviour of the perentie differed significantly to that within reference vegetation.

\section{Conclusions}

T-LoCoH is a highly effective method for constructing complex home ranges of animals, and for understanding how movement and habitat use may be influenced or constrained by environmental factors. The T-LoCoH method allowed for not only the 
construction of the perentie's total home range, but understanding the complex behavioural responses of the perentie to habitat alteration. The use of T-LoCoH is not restricted to assessments of thermal responses and behaviour of ectothermic animals but may be applied to a wide range of fauna, habitats, and disturbances. Contrary to conclusions drawn from assessments of presence and absence, which may conclude roughly equal use between restoration and reference habitats by our perentie, TLoCoH analyses allowed for the identification of differential habitat use, core usage areas, and areas with limited use, or that were avoided completely. We highlight that although restoration may be facilitating return of a high order reptilian predator, behavioural use of restoration differs from that in reference habitat. Understanding the behavioural responses animals, in addition to their presence or absence from habitats, is key to facilitating their conservation in the face of increasing rates of habitat degradation. The T-LoCoH method of home range construction provides a useful measure for understanding the complex interactions of animals with their environments. 


\section{References}

Every reasonable effort has been made to acknowledge the owners of the copyright material. I would be pleased to hear from any copyright owner who has been omitted or incorrectly acknowledged.

Attum, O.A. and Eason, P.K. (2006). Effects of vegetation loss on a sand dune lizard. The Journal of Wildlife Management 70, 27-30.

Bamford, M. (2006). Gindalbie metals n.L. And midwest corporation: Mt karara/mungada haul road; fauna assessment, Report prepared for Woodman Environmental Consulting Pty Ltd, Applecross, by M. J. and A. R. Bamford Consulting Ecologists, Kingsley, WA.

Basson, C.H., Levy, O., Angilletta, M.J. Jr. and Clusella-Trullas, S. (2017). Lizards paid a greater opportunity cost to thermoregulate in a less heterogeneous environment. Functional Ecology 31, 856-865.

Benhamou, S. and Riotte-Lambert, L. (2012). Beyond the utilization distribution: identifying home range areas that are intensively exploited or repeatedly visited. Ecological Modelling 227, 112-116.

Böhm, M., Collen, B., Baillie, J.E., Bowles, P., Chanson, J., Cox, N., Hammerson, G., Hoffmann, M., Livingstone, S.R., Ram, M. et al. (2013). The conservation status of the world's reptiles. Biological Conservation 157, 372385.

Byrne, M.E., Clint McCoy, J., Hinton, J.W., Chamberlain, M.J. and Collier, B.A. (2014). Using dynamic B rownian bridge movement modelling to measure temporal patterns of habitat selection. Journal of Animal Ecology 83, 12341243.

Chelazzi, G. and Calzolai, R. (1986). Thermal benefits from familiarity with the environment in a reptile. Oecologia 68, 557-558.

Chiarucci, A., Bacaro, G. and Scheiner, S.M. (2011). Old and new challenges in using species diversity for assessing biodiversity. Philosophical Transactions of the Royal Society B: Biological Sciences 366, 2426-2437.

Christian, K.A. and Weavers, B.W. (1994). Analysis of the activity and energetics of the lizard Varanus rosenbergi. Copeia 1994, 289-295. 
Christian, K.A., and Weavers, B.W. (1996). Thermoregulation of monitor lizards in Australia: An evaluation of methods in thermal biology. Ecological Monographs 66, 139-157.

Ciofi, C., Puswati, J., Winana, D., de Boer, M.E., Chelazzi, G. and Sastrawan, P. (2007). Preliminary analysis of home range structure in the Komodo monitor, Varanus komodoensis. Copeia 2007, 462-470.

Cogger, H. (2014). Reptiles and amphibians of Australia. CSIRO Publishing, Australia.

Cooke, S.J., Hinch, S.G., Wikelski, M., Andrews, R.D., Kuchel, L.J., Wolcott, T.G. and Butler, P.J. (2004). Biotelemetry: a mechanistic approach to ecology. Trends in Ecology \& Evolution 19, 334-343.

Cooke, S.J. (2008). Biotelemetry and biologging in endangered species research and animal conservation: relevance to regional, national, and iucn red list threat assessments. Endangered Species Research 4, 165-185.

Cross, S.L., Tomlinson, S., Craig, M.D. Dixon, K.W., and Bateman, P.W. (2019). Overlooked and undervalued: the neglected role of fauna and a global bias in ecological restoration assessments. Pacific Conservation Biology. 25, 331341.

Diemer, J.E. (1992). Home range and movements of the tortoise Gopherus polyphemus in northern Florida. Journal of Herpetology 26, 158-165.

Dobson, A.P., Bradshaw, A. and Baker, A.á. (1997). Hopes for the future: restoration ecology and conservation biology. Science 277, 515-522.

Doody, J.S., James, H., Ellis, R., Gibson, N., Raven, M., Mahony, S., Hamilton, D.G., Rhind, D., Clulow, S. and McHenry, C.R. (2014). Cryptic and complex nesting in the yellow-spotted monitor, Varanus panoptes. Journal of Herpetology 48, 363-370.

Downs, J.A. and Horner, M.W. (2008). Effects of point pattern shape on home-range estimates. The Journal of Wildlife Management 72, 1813-1818.

Flesch, J.S., Duncan, M.G., Pascoe, J.H. and Mulley, R.C. (2009). A simple method of attaching gps tracking devices to free-ranging lace monitors (Varanus varius). Herpetological Conservation and Biology 4, 411-414.

García-Muñoz, E. and Sillero, N. (2010). Two new types of noose for capturing herps. Acta Herpetologica 5, 259-264. 
Getz, W.M., Fortmann-Roe, S., Cross, P.C., Lyons, A.J., Ryan, S.J. and Wilmers, C.C. (2007) LoCoH: nonparametric kernel methods for constructing home ranges and utilization distributions. PLOS ONE 2, e207.

Green, B. (1972). Water losses of the sand goanna (Varanus gouldii) in its natural environments. Ecology 53, 452-457.

Guarino, F. (2002). Spatial ecology of a large carnivorous lizard, Varanus varius (Squamata: Varanidae). Journal of Zoology 258, 449-457.

Heard, G.W., Black, D. and Robertson, P. (2004). Habitat use by the inland carpet python (Morelia spilota metcalfei: Pythonidae): seasonal relationships with habitat structure and prey distribution in a rural landscape. Austral Ecology 29, 446-460.

Hertz, P.E., Huey, R.B. and Garland, T. Jr. (1988). Time budgets, thermoregulation, and maximal locomotor performance: Are reptiles olympians or boy scouts? American Zoologist 28, 927-938.

Hertz, P.E., Huey, R.B. and Stevenson, R. (1993). Evaluating temperature regulation by field-active ectotherms: the fallacy of the inappropriate question. The American Naturalist 142, 796-818.

Ihlow, F., Dambach, J., Engler, J.O., Flecks, M., Hartmann, T., Nekum, S., Rajaei, H. and Rödder, D. (2012). On the brink of extinction? How climate change may affect global chelonian species richness and distribution. Global Change Biology 18, 1520-1530.

Ims, R.A. (1995). Movement patterns related to spatial structures.In: Mosaic landscapes and ecological processes (Eds Hansson, L., Fahrig, L. and Merriam, G.) Pp. 85-109. Springer: Dordrecht.

Green, B., King, D. and Butler, H. (1986). Water, sodium and energy turnover in free-living perenties, Varanus giganteus. Wildlife Research 13, 589-595.

King, D. (1980). The thermal biology of free-living sand goannas (Varanus gouldii) in southern Australia. Copeia 1980, 755-767.

King, D., Green, B. and Butler, H. (1989). The activity pattern, temperature regulation and diet of Varanus giganteus on Barrow Island, Western Australia. Wildlife Research 16, 41-47.

King, D. and Green, B. (1993). Family varanidae. In: Fauna of AustraliaVol $2 a$ Amphibia \& Reptilia (Eds Glasby, C.J., Ross, G.J.B. and Beesley, P.L.). Pp. 253-260. Australian Government Publishing Service: Canberra. 
Kingsford, R., Watson, J.E., Lundquist, C., Venter, O., Hughes, L., Johnston, E., Atherton, J., Gawel, M., Keith, D.A. and Mackey, B. (2009). Major conservation policy issues for biodiversity in Oceania. Conservation Biology 23, 834-840.

Kranstauber, B., Kays, R., LaPoint, S.D., Wikelski, M. and Safi, K. (2012). A dynamic Brownian bridge movement model to estimate utilization distributions for heterogeneous animal movement. Journal of Animal Ecology 81, 738-746.

Laver, P.N. and Kelly, M.J. (2008). A critical review of home range studies. Journal of Wildlife Management 72, 290-298.

Lele, S.R., Merrill, E.H., Keim, J. and Boyce, M.S. (2013). Selection, use, choice and occupancy: clarifying concepts in resource selection studies. Journal of Animal Ecology 82, 1183-1191.

Lima, S.L. and Dill, L.M. (1990). Behavioral decisions made under the risk of predation: a review and prospectus. Canadian Journal of Zoology 68, 619640.

Lima, S.L. and Bednekoff, P.A. (1999). Temporal variation in danger drives antipredator behavior: the predation risk allocation hypothesis. The American Naturalist 153, 649-659.

Lindell, C.A. (2008). The value of animal behaviour in evaluations of restoration success. Restoration Ecology 16, 197-203.

Lyons, A.J., Turner, W.C. and Getz, W.M. (2013). Home range plus: a space-time characterization of movement over real landscapes. Movement Ecology 1, 2.

Lyons, A.J. (2014). T-locoh for r: Tutorial and users guide. Google Scholar: 2-53.

Mackenzie, D.I. (2005). What are the issues with presence-absence data for wildlife managers? The Journal of Wildlife Management 69, 849-860.

Mauritzen, M., Derocher, A.E., Pavlova, O. and Wiig, Ø. (2003). Female polar bears, Ursus maritimus, on the barents sea drift ice: Walking the treadmill. Animal Behaviour 66, 107-113.

Moro, D. and MacAulay, I. (2014). Computer-aided pattern recognition of large reptiles as a noninvasive application to identify individuals. Journal of Applied Animal Welfare Science 17, 125-135. 
Obbard, M.E., Pond, B.A. and Perera, A. (1998). Preliminary evaluation of GPS collars for analysis of habitat use and activity patterns of black bears. Ursus 10, 209-217.

Ofstad, E.G., Herfindal, I., Solberg, E.J., Heim, M., Rolandsen, C.M. and Sæther, B.E. (2019). Use, selection, and home range properties: complex patterns of individual habitat utilization. Ecosphere 10, p.e02695.

Pianka, E.R. (1994). Comparative ecology of Varanus in the great victoria desert. Australian Journal of Ecology 19, 395-408.

Pianka, E.R., King, D. and King, R.A. (2004). Varanoid Lizards of the World. Indiana University Press, Indiana.

Pimley, E.R., Bearder, S.K. and Dixson, A.F. (2005). Home range analysis of Perodicticus potto edwardsi and Sciurocheirus cameronensis. International Journal of Primatology 26, p.191-206.

Price-Rees, S.J. and Shine, R. (2011). A backpack method for attaching GPS transmitters to bluetongue lizards (Tiliqua, Scincidae). Herpetological Conservation and Biology 6, 155-161.

R Core Team (2016). R: A language and environment for statistical computing. $R$ Foundation for Statistical Computing, Vienna, Austria. Available at: https://www.R-project.org/.

Rocha, C.F.D. (1999). Home range of the tropidurid lizard Liolaemus lutzae: sexual and body size differences. Revista Brasileira de Biologia 59, 125-130.

Row, J.R. and Blouin-Demers, G. (2006). Thermal quality influences habitat selection at multiple spatial scales in milksnakes. Ecoscience 13, 443-450.

Sears, M.W., Raskin, E. and Angilletta, M.J. Jr. (2011). The world is not flat: defining relevant thermal landscapes in the context of climate change. Integrative and Comparative Biology 51, 666-675.

Seebacher, F. and Franklin, C.E. (2012). Determining environmental causes of biological effects: The need for a mechanistic physiological dimension in conservation biology. Philosophical Transactions of the Royal Society B: Biological Sciences 367, 1607-1614.

Semlitsch, R.D. (1981). Terrestrial activity and summer home range of the mole salamander (Ambystoma talpoideum). Canadian Journal of Zoology 59, 315322. 
Schwanz, L.E. and Janzen, F.J. (2008). Climate change and temperature-dependent sex determination: can individual plasticity in nesting phenology prevent extreme sex ratios? Physiological and Biochemical Zoology 81, 826-834.

Sinervo, B., Mendez-De-La-Cruz, F., Miles, D., Heulin, B., Bastiaans, E., VillagránSanta Cruz, M., Lara-Resendiz, R., Martínez-Méndez, N., CalderónEspinosa, M., Meza-Lázaro, R. et al. (2010). Erosion of lizard diversity by climate change and altered thermal niches. Science 328, 894-899.

Stark, D.J., Vaughan, I.P., Ramirez Saldivar, D.A., Nathan, S.K.S.S. and Goossens, B. (2017). Evaluating methods for estimating home ranges using gps collars: a comparison using proboscis monkeys (Nasalis larvatus). PloS ONE 12, $\mathrm{e} 0174891$.

Tarszisz, E., Tomlinson, S., Harrison, M.E., Morrogh-Bernard, H.C. and Munn, A.J. (2018). An ecophysiologically informed model of seed dispersal by orangutans: linking animal movement with gut passage across time and space. Conservation Physiology 6, coy013.

Thomas, B., Holland, J.D. and Minot, E.O. (2011). Wildlife tracking technology options and cost considerations. Wildlife Research 38, 653-663.

Tuff, K.T., Tuff, T. and Davies, K.F. (2016). A framework for integrating thermal biology into fragmentation research. Ecology Letters 19, 361-374.

Vernet, R., Lemire, M. and Grenot, C. (1988). Field studies on activity and water balance of a desert monitor Varanus griseus (Reptilia, Varanidae). Journal of Arid Environments 15, 81-90.

Webb, J., Harlow, P. and Pike, D. (2014). Australian reptiles and their conservation. In Gregory I. Holwell NM ed, Austral ark: The state of wildlife in Australia and New Zealand. Cambridge University Press: United Kingdom, Pp. 354381.

Wikramanayake, E.D. and Dryden, G.L. (1993). Thermal ecology of habitat and microhabitat use by sympatric Varanus bengalensis and V. salvator in Sri Lanka. Copeia 1993, 709-714.

Worton, B.J. (1987). A review of models of home range for animal movement. Ecological Modelling 38, 277-298. 